\title{
Treatment of complex anterior cerebral artery aneurysms with Pipeline flow diversion: mid-term results
}

\author{
Guilherme Dabus, ${ }^{1,2,3}$ Jonathan A Grossberg, ${ }_{1}^{4}$ C Michael Cawley, ${ }_{1}^{4}$ Jacques E Dion, ${ }^{4}$ \\ Ajit S Puri, ${ }^{5}$ Ajay K Wakhloo, ${ }^{5}$ Douglas Gonsales, ${ }^{6}$ Pedro Aguilar-Salinas, ${ }^{6}$ \\ Eric Sauvageau, ${ }^{6}$ Italo Linfante, ${ }^{1,2,3}$ Ricardo A Hanel $^{6}$
}

\begin{abstract}
${ }^{1}$ Miami Cardiac \& Vascular Institute, Florida International University, Miami, Florida, USA ${ }^{2}$ Baptist Neuroscience Center, Florida International University, Miami, Florida, USA

${ }^{3}$ Herbert Wertheim College of Medicine, Florida International University, Miami, Florida, USA ${ }^{4}$ Departments of Radiology and Neurosurgery, Emory University, Atlanta, Georgia, USA

${ }^{5}$ Department of Radiology, University of Massachusetts, Worcester, Massachusetts, USA ${ }^{6}$ Baptist Neurological Institute, Baptist Health System, Jacksonville, Florida, USA
\end{abstract}

\section{Correspondence to}

Dr Guilherme Dabus, Miami Cardiac \& Vascular Institute, 8900 N Kendall Drive, Miami, FL 33176, USA; gdabus@gmail.com

Received 13 May 2016 Revised 12 June 2016 Accepted 20 June 2016 Published Online First 5 July 2016

\section{ABSTRACT}

Background The off-label use of flow diverters in the treatment of distal aneurysms continues to be debated. Objective To report our multicenter experience in the treatment of complex anterior cerebral artery aneurysms with the Pipeline embolization device (PED).

Methods The neurointerventional databases of the four participating institutions were retrospectively reviewed for aneurysms treated with PED between October 2011 and January of 2016. All patients treated for anterior cerebral artery aneurysms were included in the analysis. Clinical presentation, location, type, vessel size, procedural complications, clinical and imaging follow-up were included in the analysis.

Results Twenty patients (13 female) with 20 aneurysms met the inclusion criteria in our study. Fifteen aneurysms were classified as saccular and five as fusiform (mean size $7.3 \mathrm{~mm}$ ). Thirteen aneurysms were located in the anterior communicating region (ACOM or $A 1 / 2$ junction), six were $A 2$-pericallosal, and one was located in the A1 segment. Six patients had presented previously with subarachnoid hemorrhage and had their aneurysms initially clipped or coiled. There was one minor event (a small caudate infarct) and one major event (intraparenchymal hemorrhage). Sixteen of the 20 patients had angiographic follow-up (mean 10 months). Eleven aneurysms were completely occluded, one had residual neck, and four had residual aneurysm filling.

Conclusions The treatment of complex anterior cerebral artery aneurysms with the PED as an alternative for patients who are not good candidates for conventional methods is technically feasible and safe. Mid-term results are promising but larger series with long-term follow-up are required to assess its effectiveness.

\section{INTRODUCTION}

The off-label use of flow diverters for the treatment of distal aneurysms remains a matter of debate. Several reports have demonstrated that the treatment of these types of aneurysm is feasible and safe, whereas others have shown an increase in complication rates for such procedures. ${ }^{1-6}$ Most of these reports are small and present combined locations, such as distal internal carotid arteries, middle cerebral arteries, anterior cerebral arteries, and posterior cerebral arteries. ${ }^{1-6}$ Anterior cerebral artery aneurysms, particularly those located in the anterior communicating (ACOM) region, are known to present increased hemorrhagic risk compared with other intracranial locations. ${ }^{7} 8$ Conventional microsurgical and endovascular techniques such as clipping and coil embolization with or without assistance (balloon or stent) are the mainstay for the treatment of such aneurysms. However, complex aneurysms, particularly those fusiform in shape, large or giant in size, with a wide neck or with branches incorporated as well as those that failed initial treatment (recurrent aneurysms after clipping or coiling) pose significant technical challenges for conventional techniques. ${ }^{9-14}$ We report our multicenter experience with the Pipeline embolization device (PED) for the treatment of complex anterior cerebral artery aneurysms not felt to be good candidates for conventional methods.

\section{METHODS}

After institutional review board approval was obtained, the neurointerventional databases of the participating institutions were retrospectively reviewed for aneurysms treated with PED between October 2011 and January of 2016 in four highvolume centers (>100 aneurysms/year treated by endovascular techniques). All patients who were treated for anterior cerebral artery aneurysms were included in the analysis.

Clinical, procedural, and angiographic data, including aneurysm size and location, follow-up angiographic occlusion, and clinical follow-up data were analyzed. Aneurysms were classified according to their morphology (saccular or fusiform) and location (A1, ACOM region, or A2-pericallosal). Aneurysm size was determined by the largest diameter. The smallest and largest arterial diameters covered by the PED were also recorded. All intraprocedural and periprocedural complications were collected and reported. Minor events were considered if symptoms resolved within 7 days and major events if symptoms were present after 7 days.

All procedures were performed following written informed consent. All patients were premedicated with dual antiplatelet therapy. Platelet function tests were not mandatory but were performed in 17 of the 20 patients. All procedures were performed by experienced neuroendovascular 
surgeons with significant PED experience. Intraprocedural heparinization was performed to achieve an activated clotting time $>250$ s. Heparin was discontinued on conclusion of the procedure. Dual antiplatelet therapy was continued for 6 months after the procedure and, subsequently, treatment was continued with a single agent.

Aneurysm occlusion was classified using the Raymond scale. Clinical outcome was defined using the modified Rankin Scale (mRS) score at the last follow-up visit, as assessed and reported by the treatment center.

\section{RESULTS}

Twenty patients (13 female and 7 male) with 20 aneurysms met the inclusion criteria in our study. Table 1 summarizes the major findings of the study. All cases were felt to not be ideal candidates for conventional surgical or endovascular techniques. Fifteen aneurysms were classified as saccular and five as fusiform. Aneurysm size range was $1.3-21.4 \mathrm{~mm}$ (mean $7.3 \mathrm{~mm}$ ). Thirteen aneurysms were located in the ACOM region (ACOM or $\mathrm{A} 1 / 2$ junction), six were $\mathrm{A} 2$-pericallosal, and one was located in the A1 segment. Six patients had presented previously with subarachnoid hemorrhage and had their aneurysms initially clipped or coiled. The minimum native artery diameter ranged from 1 to $2.6 \mathrm{~mm}$ (mean $1.8 \mathrm{~mm}$ ). All deployments were successful. One patient had a small caudate infarct 48 hours after the procedure with complete recovery (minor event) (figure 1). One patient had a large intraparenchymal hemorrhage distal to the site of the aneurysm (ACOM), in the parietal region, 48 hours after the procedure and died as a consequence (major event). Angiographic follow-up (mean 10 months) was available in 16 of the 20 patients $(80 \%)$. Eleven aneurysms were completely occluded, one had residual neck, and four had residual aneurysm filling. One patient had asymptomatic 50\% in-stent stenosis, which was managed by continuing the dual antiplatelet regimen. No aneurysm bleeds or re-bleeds occurred during the follow-up period. At the last clinical follow-up, only one patient had a worse mRS score changed from 0 (pretreatment) to 6 , two patients had mRS of 3 (stable from a prior procedure), and all others had mRS 0 or 1.

Table 1 Major findings of the study

\begin{tabular}{|c|c|c|c|c|c|c|c|c|c|}
\hline $\begin{array}{l}\text { Patient } \\
\text { No }\end{array}$ & Age & $\begin{array}{l}\text { mRS } \\
\text { before }\end{array}$ & $\begin{array}{l}\text { Aneurysm } \\
\text { location }\end{array}$ & $\begin{array}{l}\text { Aneurysm size } \\
(\mathrm{mm})\end{array}$ & $\begin{array}{l}\text { Previous } \\
\text { treatment }\end{array}$ & $\begin{array}{l}\text { Neurological } \\
\text { complications }\end{array}$ & $\begin{array}{l}\text { Angiographic F/U } \\
\text { (months) }\end{array}$ & $\begin{array}{l}\text { Angio F/U- } \\
\text { Raymond Scale }\end{array}$ & $\begin{array}{l}\mathrm{mRS} \text { at } \\
\text { last } \mathrm{F} / \mathrm{U}\end{array}$ \\
\hline 1 & $\begin{array}{l}\text { Early } \\
30 \mathrm{~s}\end{array}$ & 0 & ACOM region & 2 & Yes (coiling) & None & 21 & 1 & 0 \\
\hline 2 & $\begin{array}{l}\text { Early } \\
70 \mathrm{~s}\end{array}$ & 3 & Pericallosal & 7.4 & No & None & 14 & $\begin{array}{l}3 \text { (improved- } \\
\text { decrease in filling) }\end{array}$ & 3 \\
\hline 3 & $\begin{array}{l}\text { Early } \\
70 \mathrm{~s}\end{array}$ & 0 & ACOM region & 6 & No & Minor event & 6 & $\begin{array}{l}1 \text { ( } 50 \% \text { in-stent } \\
\text { stenosis) }\end{array}$ & 0 \\
\hline 4 & $\begin{array}{l}\text { Early } \\
50 \mathrm{~s}\end{array}$ & 3 & ACOM region & 5.1 & Yes (coiling) & None & $\mathrm{N} / \mathrm{A}$ & N/A & 3 \\
\hline 5 & $\begin{array}{l}\text { Early } \\
70 \mathrm{~s}\end{array}$ & 0 & $\mathrm{~A} 2$ & 6.2 & Yes (coiling) & None & 12 & 1 & 0 \\
\hline 6 & $\begin{array}{l}\text { Late } \\
60 \mathrm{~s}\end{array}$ & 0 & ACOM region & 9.7 & No & None & 12 & 1 & 0 \\
\hline 7 & $\begin{array}{l}\text { Early } \\
60 \mathrm{~s}\end{array}$ & 0 & ACOM region & 8.8 & No & None & 6 & 1 & 0 \\
\hline 8 & $\begin{array}{l}\text { Mid } \\
50 \mathrm{~s}\end{array}$ & 0 & $A 2$ & 12.3 & No & None & N/A & N/A & 0 \\
\hline 9 & $\begin{array}{l}\text { Early } \\
50 \mathrm{~s}\end{array}$ & 0 & ACOM region & 21.4 & No & None & 6 & 1 & 0 \\
\hline 10 & $\begin{array}{l}\text { Early } \\
50 \text { s }\end{array}$ & 0 & ACOM region & 11.1 & No & Major event & N/A-MRS6 & $\mathrm{N} / \mathrm{A}$ & 6 \\
\hline 11 & $\begin{array}{l}\text { Late } \\
40 \mathrm{~s}\end{array}$ & 0 & ACOM region & 2.2 & No & None & 6 & 1 & 0 \\
\hline 12 & $\begin{array}{l}\text { Early } \\
80 \mathrm{~s}\end{array}$ & 0 & ACOM region & 5.5 & No & None & 15 & 3 & 0 \\
\hline 13 & $\begin{array}{l}\text { Mid } \\
70 s\end{array}$ & 1 & $A 2$ & 5.1 & Yes (coiling) & None & 12 & 2 & 0 \\
\hline 14 & $\begin{array}{l}\text { Early } \\
50 \mathrm{~s}\end{array}$ & 2 & ACOM region & 1.3 & Yes (clipping) & None & 13 & 1 & $0 / 1$ \\
\hline 15 & $\begin{array}{l}\text { Mid } \\
30 \mathrm{~s}\end{array}$ & 0 & ACOM region & 6 & Yes (clipping) & None & 9 & 1 & 0 \\
\hline 16 & $\begin{array}{l}\text { Early } \\
70 \mathrm{~s}\end{array}$ & 0 & ACOM region & 15 & No & None & 12 & 1 & 0 \\
\hline 17 & $\begin{array}{l}\text { Early } \\
80 \mathrm{~s}\end{array}$ & 1 & Pericallosal & 5 & No & None & 3 & 3 & 0 \\
\hline 18 & $\begin{array}{l}\text { Early } \\
70 \mathrm{~s}\end{array}$ & 0 & A1 & 7.2 & No & None & 12 & 1 & 0 \\
\hline 19 & $\begin{array}{l}\text { Late } \\
60 \mathrm{~s}\end{array}$ & 0 & ACOM region & 4.3 & No & None & 1 & 3 & 0 \\
\hline 20 & $\begin{array}{l}\text { Early } \\
60 \mathrm{~s}\end{array}$ & 0 & $A 2$ & 4.3 & No & None & $\mathrm{N} / \mathrm{A}$ & $\mathrm{N} / \mathrm{A}$ & 0 \\
\hline
\end{tabular}

ACOM, anterior communicating; F/U, follow-up; mRS, modified Rankin Scale. 


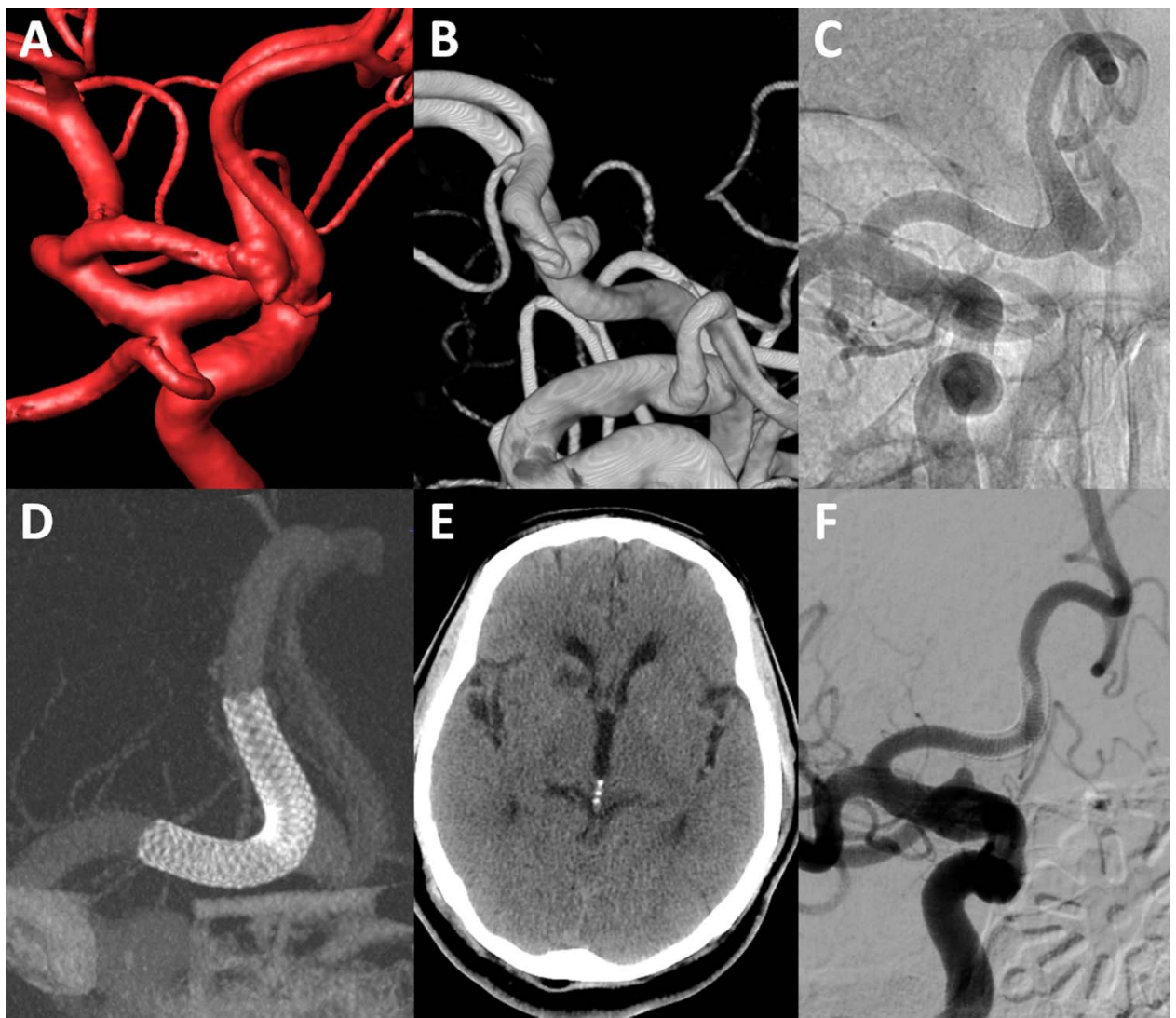

Figure 1 Fusiform, irregular $6 \mathrm{~mm}$ aneurysm at the anterior communicating region (A and B). A Pipeline embolization device (PED) was successfully positioned covering the aneurysm (C and D). Note the compression of the PED cells in the inner curvature of the A1-A2 junction (D). Patient developed a small caudate infarct 48 hours after the procedure, with complete recovery (minor event) (E). A 6-month follow-up angiography revealed complete occlusion of the aneurysm with asymptomatic $50 \%$ in-stent stenosis (F).

\section{DISCUSSION}

Anterior cerebral artery aneurysms, including ACOM complex aneurysms, have increased rates of rupture compared with other locations. $^{7} 8$ The UCAS study followed up 6697 newly diagnosed aneurysms for a total of 11660 aneurysm-years. This study demonstrated that the HR for rupture was significantly higher for aneurysms of the ACOM region $(\mathrm{HR}=2.02)$, which also had a tendency to rupture at smaller sizes. ${ }^{7}$ In another natural history study with long-term follow-up (median 21 years), Juvela $e t a l^{8}$ reported that the location of the aneurysm in the ACOM artery (adjusted HR=3.73) was an independent predictor of aneurysm rupture. The reason why ACOM region aneurysms rupture at higher rates and smaller sizes compared with other locations is not well understood. Matsukawa et $a l^{9}$ studied the morphological features of 140 ACOM region aneurysms, of which 78 were ruptured. Multivariate logistic regression analysis showed that aneurysm dome projecting anteriorly $(\mathrm{OR}=6.0, \mathrm{p}=0.0012)$, the presence of a bleb(s) $(\mathrm{OR}=22, \mathrm{p}<0.0001)$, and an aneurysm size $\geq 5 \mathrm{~mm}(\mathrm{OR}=3.16$, $\mathrm{p}=0.035)$ were significantly associated with rupture. ${ }^{9}$ Tarulli and Fox ${ }^{12}$ also demonstrated that asymmetric A1 configurations facilitate the development of ACOM aneurysms by hemodynamic stress $(\mathrm{OR}=17.8)$. In our series, six patients had presented previously with subarachnoid hemorrhage and had their aneurysms initially clipped $(n=2)$ or coiled $(n=4)$.

Conventional microsurgical and endovascular techniques are the mainstays of treatment for aneurysms located in the anterior cerebral artery. However, complex aneurysms, particularly those fusiform in shape, large or giant in size, with a wide neck or with branches incorporated as well as those that failed initial treatment (recurrent aneurysms after clipping or coiling) pose significant technical challenges for conventional techniques. ${ }^{9-14}$ In our series five patients had fusiform lesions, another six had been previously treated with either clipping $(n=2)$ or coiling $(\mathrm{n}=4)$, and in four cases the aneurysm size was $>10 \mathrm{~mm}$ with a wide neck. Endovascular treatment of anterior cerebral artery aneurysms has been performed over the past 20 years, mostly with coil embolization with or without adjunctive assistance of balloons or stents. Fang et al performed a meta-analysis consisting of 1552 endovascularly treated ACOM artery aneurysms. The rate of immediate and long-term complete and nearcomplete angiographic occlusion was $88 \%$ and $85 \%$, respectively. Intraprocedural rupture occurred in $4 \%$, and $7 \%$ required re-treatment. Overall procedure-related morbidity and mortality were $6 \%$ and $3 \%$, respectively. ${ }^{11}$

Morphological aspects of the aneurysm and anterior cerebral artery configuration also seem to play a role in aneurysm recurrence. In a study on the effects of circle of Willis anatomic variations on angiographic and clinical outcomes of coiled ACOM artery aneurysms, Tarulli et $a l^{13}$ demonstrated a statistically significant increase in neck remnants and progressive aneurysm sac filling with the A1 dominant configuration, suggesting that this anatomical-hemodynamic feature contributes to aneurysm formation, growth, and instability after coiling treatment. Another study evaluating morphological features of ACOM region aneurysms demonstrated that, among the features studied (direction of the dome, dome size, dome to neck ratio, presence of irregularity, and angle between A1 segment of the anterior cerebral 
Figure 2 Ruptured anterior communicating (ACOM) region aneurysm that was initially treated with coil embolization (A and $B$ ). Note the presence of a daughter sac projecting close to the neck of the aneurysm (arrow A). Immediate angiographic result following coil embolization demonstrated complete occlusion of the aneurysm and daughter sac (B). A 4-month follow-up angiogram revealed recurrence with re-opacification of the daughter sac (arrow C). The patient was then treated with the placement of a Pipeline embolization device. A 21-month follow-up showed complete occlusion of the aneurysm and its daughter sac (D). Contralateral injection demonstrated no opacification of the aneurysm across the ACOM region (not shown).

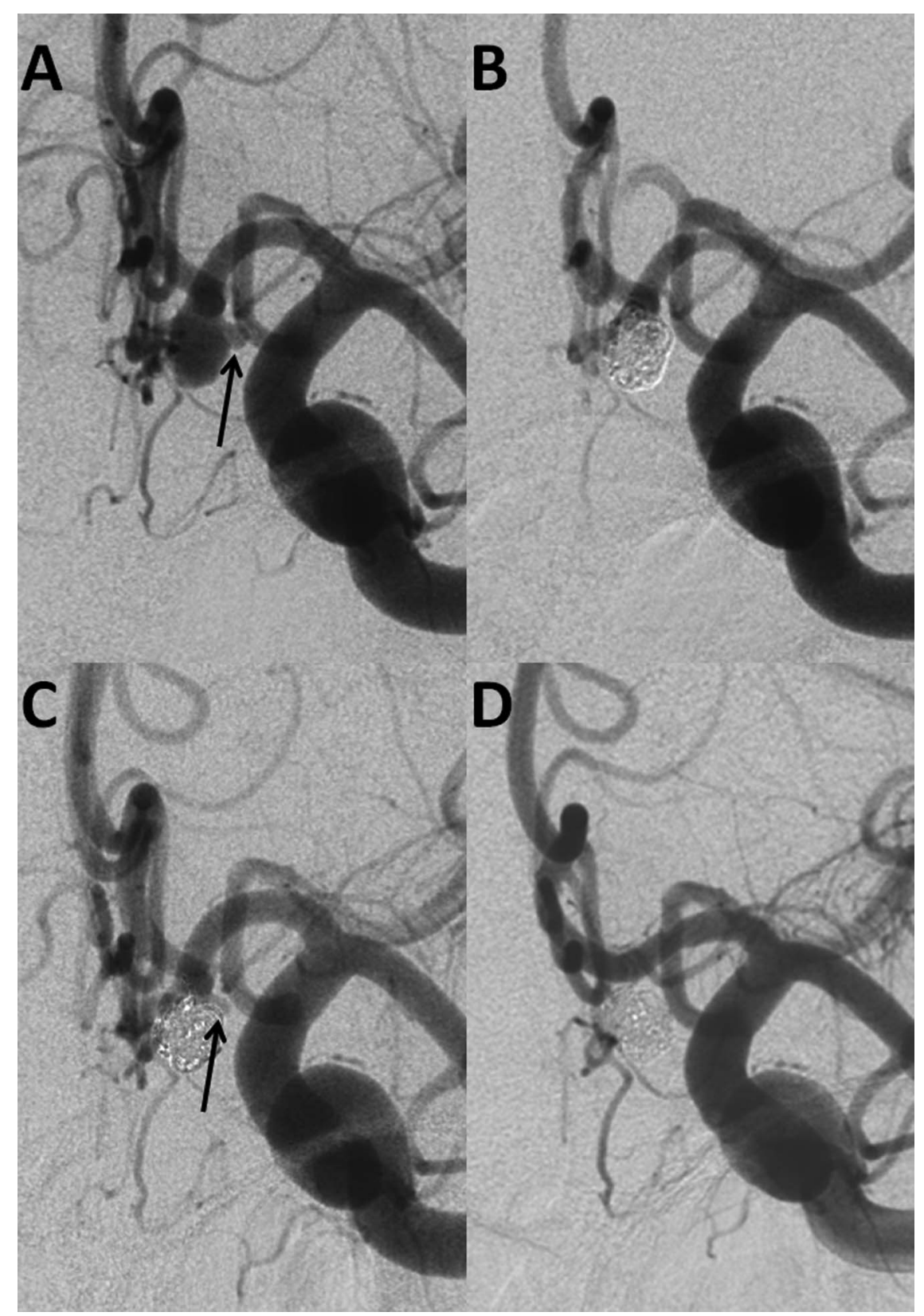

artery and the internal carotid artery), only superior dome direction was associated with incomplete occlusion. ${ }^{10}$ In our series, six patients $(30 \%)$ had had previous treatments (clipping or coiling) and were treated with the Pipeline device for recurrent/ residual aneurysms.

Several reports have examined the use of flow diverter stents for the treatment of aneurysms in the distal intracranial vasculature; its use, however, is still a matter of debate.

One small series examined the use of such devices specifically in the anterior cerebral artery location. ${ }^{1}$ In that series, eight aneurysms (three located on the A1 segment, three on the ACOM artery, and two on the A2-A3 junction) were treated. In three cases, the flow diverter was used to treat angiographic recurrence after coiling. No clinical complication was recorded. Total occlusion was seen in five aneurysms (71.4\%) and neck remnant in two $(28.6 \%)$ cases with a mean angiographic follow-up of 9.7 months. ${ }^{1}$

Lin et al reported a series of 28 distal anterior circulation aneurysms treated with the PED, of which eight were located in the anterior cerebral artery. Clinical follow-up was available for an average of 10.7 months. Twenty-seven patients had follow-up neurovascular imaging: 21 aneurysms had complete occlusion (78\%). Periprocedural complications (<30 days) occurred in three patients $(10.7 \%)$. The authors concluded that PED can be used in the treatment of distal anterior circulation aneurysms with difficult anatomy for conventional surgical or endovascular techniques. ${ }^{2}$ Other series on distal anterior circulation aneurysms have shown similar results.

Martínez-Galdámez et al studied 25 patients with anterior circulation aneurysms treated with a PED. Three neurological events were noted (two minor-resolved within 7 days; and one major). No aneurysm ruptures or parenchymal hemorrhages occurred during follow-up. Three intraprocedural complications resolved without clinical consequences. Six-month follow-up angiograms showed complete occlusion in 14 (64\%). There were six cases of in-stent stenosis (27\%), of which one case was symptomatic. $^{4}$ 


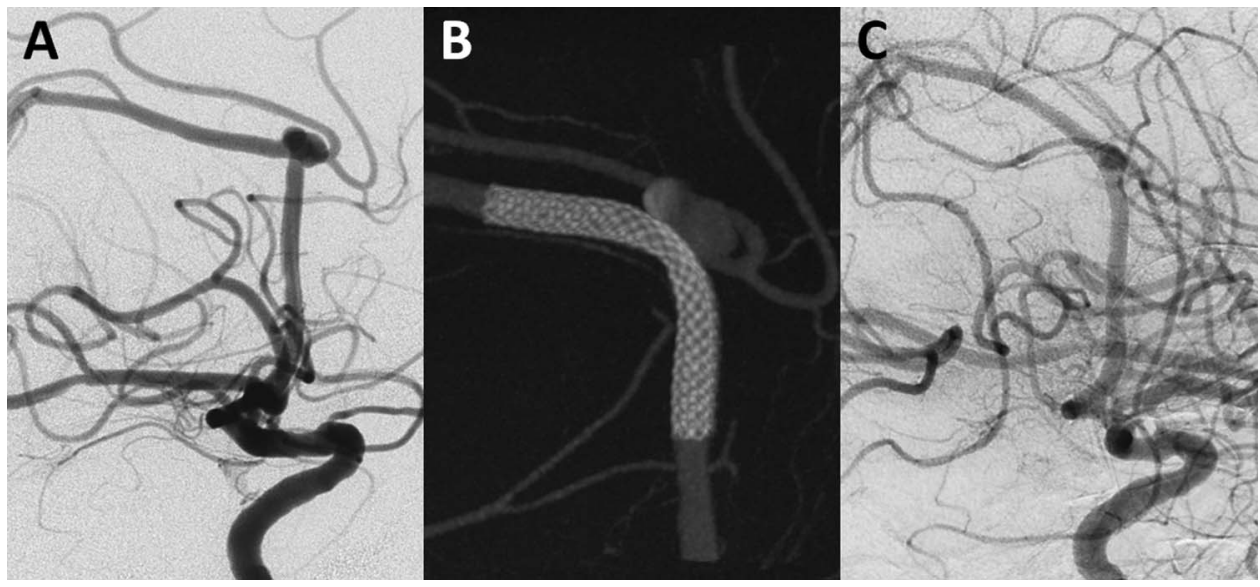

Figure 3 The images demonstrate a $7.4 \mathrm{~mm}$ lobulated pericallosal artery with branch incorporated at its base (A). A Pipeline embolization device was successfully placed, with no complications (B). A 14-month follow-up showed decreased but persistent filling of the aneurysm sac, which had decreased in size $(C)$.

In one multicenter series, seven patients were treated with a single PED (five aneurysms were located in the anterior cerebral artery). The mean parent vessel size was $1.9 \mathrm{~mm}$. In this series there were no peri- or post-procedural complications. Angiographic follow-up demonstrated complete aneurysm occlusion in all aneurysms. ${ }^{3}$

Pistocchi et al reported 30 aneurysms treated with Silk or Pipeline flow diversion in 26 patients. Of these 30 aneurysms, 21 were located in the anterior cerebral arteries in 17 patients. Overall neurological complications were noted in $11.1 \%(7.4 \%$ reversible and $3.7 \%$ permanent). No aneurysms bled or re-bled after treatment. At follow-up (mean 13 months), 79\% of the aneurysms were totally occluded. ${ }^{6}$ On the other hand, one series reported the use of flow diverters in the treatment of middle cerebral artery bifurcation aneurysms with ischemic complications, as confirmed by MR imaging, occurring in $43 \%$ of the patients and leading to a procedure-related morbidity of 21\%. Angiographic follow-up (mean 16 months) demonstrated complete occlusion in $62 \%$ of the aneurysms. ${ }^{5}$

To our knowledge, our study represents the largest series of patients with PED-treated aneurysms of the anterior cerebral artery. Compared with the other series, we observed two neurological events (10\%)—one was a small caudate infarct 48 hours after the procedure, with complete recovery (minor event) and one a large intraparenchymal hemorrhage distal to the site of the aneurysm (ACOM), in the parietal region, 48 hours after the procedure, resulting in a follow-up $\mathrm{mRS}$ of 6 (major event). Although a recent analysis of ischemic complications in the IntrePED study showed that fusiform aneurysms were the only variable independently associated with postoperative stroke, ${ }^{15}$ the small caudate infarct in our series (during the treatment of an irregular fusiform aneurysm) could be better explained by occlusion of the recurrent artery of Heubner at the inner curvature of the A1-A2 junction, which is the region where flow diverter cells are the most compressed (figure 1). On the other hand, the large intraparenchymal hemorrhage that happened 48 hours after the procedure and resulted in our only death is difficult to explain. Intraparenchymal hemorrhage following flow diverter placement is a well-known phenomenon that is poorly understood. Reported rates may be as high as $8.5 \% .^{16} 17$ Several series have studied this topic and postulated hypotheses include hemodynamic and flow changes, antiplatelet management, and foreign body emboli. ${ }^{16} 18$ These are all theoretical possibilities in our patient. A recent large multicenter series demonstrated no correlation between aneurysm size and location with intraparenchymal hemorrhage. ${ }^{16}$

For angiographic outcome, our series showed complete occlusion in $69 \%$ and complete or near-complete occlusion in $75 \%$ of cases with a mean follow-up of 10 months (figures 1 and 2). In four patients residual aneurysm sac filling was seen (figure 3).

For clinical outcome, only one patient had a poorer mRS at follow-up than at baseline (death-mRS of 6). All other patients were stable (two patients with an mRS of 3 and all others 0 or 1). These results are in accordance with other similar published series of aneurysms in small distal intracranial vessels. ${ }^{1-4} 6$ As these patients were felt not to be good candidates for conventional endovascular or surgical treatments, comparison with such series is not useful.

Our study has some limitations. First, since the use of flow diverter stents in anterior cerebral arteries is uncommon, the number of patients is relatively small, although similar or larger than other reported case series. Second, the retrospective nature introduces selection bias. Lastly, like most of the other reported series, the team of treating physicians adjudicated the results.

\section{CONCLUSION}

Our study indicates that treatment of complex anterior cerebral artery aneurysms with the PED as an alternative for patients who are not good candidates for conventional methods is technically feasible and safe. Mid-term results are promising but larger series with long-term follow-up are required to assess its effectiveness.

Contributors Conception: GD, JAG, ASP, and RAH; acquisition and interpretation of the data: GD, IL, JAG, CMC, JED, ASP, AKW, DG, PA-S, ES, and RAH; drafting: GD; revising: GD, IL, JAG, ASP, and RAH; final approval: GD, IL, JAG, CMC, JED, ASP, AKW, DG, PA-S, ES, and RAH.

Competing interests GD, IL, ASP, and RAH are consultants and proctors for Medtronic Neurovascular.

Ethics approval Institutional review boards.

Provenance and peer review Not commissioned; externally peer reviewed.

\section{REFERENCES}

1 Clarençon F, Di Maria F, Gabrieli J, et al. Flow diverter stents for the treatment of anterior cerebral artery aneurysms: safety and effectiveness. Clin Neuroradiol 2015. 
2 Lin N, Lanzino G, Lopes DK, et al. Treatment of distal anterior circulation aneurysms with the Pipeline embolization device: a US multicenter experience. Neurosurgery 2016;79:14-22.

3 Puri AS, Massari F, Asai T, et al. Safety, efficacy, and short-term follow-up of the use of Pipeline ${ }^{\mathrm{TM}}$ embolization device in small $(<2.5 \mathrm{~mm})$ cerebral vessels for aneurysm treatment: single institution experience. Neuroradiology 2016;58:267-75.

4 Martínez-Galdámez M, Romance A, Vega P, et al. Pipeline endovascular device for the treatment of intracranial aneurysms at the level of the circle of Willis and beyond: multicenter experience. J Neurointerv Surg 2015;7:816-23.

5 Caroff J, Neki H, Mihalea C, et al. Flow-diverter stents for the treatment of saccular middle cerebral artery bifurcation aneurysms. AJNR Am J Neuroradiol 2016:37:279-84.

6 Pistocchi S, Blanc R, Bartolini B, et al. Flow diverters at and beyond the level of the circle of Willis for the treatment of intracranial aneurysms. Stroke 2012;43:1032-8.

7 Morita A, Kirino T, Hashi K, et al. The natural course of unruptured cerebral aneurysms in a Japanese cohort. N Engl J Med 2012;366:2474-82.

8 Juvela S, Poussa $\mathrm{K}$, Lehto $\mathrm{H}$, et al. Natural history of unruptured intracranial aneurysms: a long-term follow-up study. Stroke 2013;44:2414-21.

9 Matsukawa $\mathrm{H}$, Uemura A, Fujii $\mathrm{M}$, et al. Morphological and clinical risk factors for the rupture of anterior communicating artery aneurysms. J Neurosurg 2013;118:978-83.

10 Uemura A, Kamo M, Matsukawa H. Angiographic outcome after endovascular therapy for anterior communicating artery aneurysms: correlation with vascular morphological features. Jpn J Radiol 2012;30:624-7.
11 Fang S, Brinjikji W, Murad MH, et al. Endovascular treatment of anterior communicating artery aneurysms: a systematic review and meta-analysis. AJNR Am J Neuroradiol 2014;35:943-7.

12 Tarulli E, Fox AJ. Potent risk factor for aneurysm formation: termination aneurysms of the anterior communicating artery and detection of $A 1$ vessel asymmetry by flow dilution. AJNR Am J Neuroradiol 2010;31:1186-91.

13 Tarulli E, Sneade M, Clarke A, et al. Effects of circle of Willis anatomic variations on angiographic and clinical outcomes of coiled anterior communicating artery aneurysms. AJNR Am J Neuroradiol 2014;35:1551-5.

14 Abla AA, Lawton MT. Anterior cerebral artery bypass for complex aneurysms: an experience with intracranial-intracranial reconstruction and review of bypass options. J Neurosurg 2014;120:1364-77.

15 Brinjikji W, Lanzino G, Cloft HJ, et al. Risk factors for ischemic complications following Pipeline embolization device treatment of intracranial aneurysms: results from the IntrePED study. AJNR Am J Neuroradiol 2016.

16 Kallmes DF, Hanel $R$, Lopes $D$, et al. International retrospective study of the Pipeline embolization device: a multicenter aneurysm treatment study. AJNR Am J Neuroradiol 2015;36:108-15.

17 Cruz JP, Chow M, O'Kelly C, et al. Delayed ipsilateral parenchymal hemorrhage following flow diversion for the treatment of anterior circulation aneurysms. AJNR Am J Neuroradiol 2012;33:603-8.

$18 \mathrm{Hu}$ YC, Deshmukh VR, Albuquerque FC, et al. Histopathological assessment of fatal ipsilateral intraparenchymal hemorrhages after the treatment of supraclinoid aneurysms with the Pipeline embolization device. J Neurosurg 2014;120:365-74. 